\title{
Shipping and COVID-19: protecting seafarers as frontline workers
}

\section{Cleopatra Doumbia-Henry ${ }^{1}$}

Received: 25 May 2020 / Accepted: 31 August 2020 / Published online: 24 September 2020

(C) World Maritime University 2020

\begin{abstract}
The article provides an overview of the impact on and the response to the COVID-19 pandemic on the maritime industry - merchant shipping, the cruise industry and ports as at the end of July 2020. With shipping being responsible for $80 \%$ of global trade, the article addresses issues relating to the response of the maritime industry, governments and international organizations to the pandemic. It also addresses the impact of the pandemic on the world's almost 2 million seafarers who as key workers enable global trade. The article examines the serious challenges seafarers have faced relating to quarantine requirements, restrictions on border crossings with border closures, repatriation and crew changeovers, abandonment, renewals of certificates and licencing of seafarers, resupply and ship surveys. The article includes the response of governments and that of United Nations agencies and in particular the World Health Organization, the International Maritime Organization, the International Labour Organization and the International Civil Aviation Organization. The significant role played by the maritime industry in providing substantive guidance is commended. The article concludes that COVID-19 will continue to have a huge impact on the maritime industry and on world trade for the foreseeable future. The expectation is that the industry will hopefully emerge stronger and become more robust to enable world trade to be efficient and sustainable. It is also expected that the pandemic will enable a greater recognition of the world's seafarers who facilitate world trade, while ensuring a better future for humanity.
\end{abstract}

Keywords Ships including cruise ships · Ports · Crew changovers · Seafarers' identity documents convention - Maritime labour convention - Repatriation - Abandonment of seafarers · UN Agencies · Governments · Maritime industry

Seafarers deliver so much for us, we have to deliver for them. Kitack Lim, IMO Secretary-General

Cleopatra Doumbia-Henry

president@wmu.se

1 World Maritime University, Fiskehamnsgatan 1, 21118 Malmö, Sweden 


\section{Introduction}

The outbreak of COVID-19 in December 2019 has had a devastating impact on the world, sparing no country. The pandemic, a twenty-first century global calamity, is a true reflection of the global economy and global village in which we live. It has led to a total shutdown of the world for months, with over 7 million confirmed cases and more than 511,000 deaths as at 1 July $2020 .^{1}$ It has affected lives worldwide and has seriously impacted the global economy and the global supply chain, including shipping and the world of work.

Shipping is the most global of industries. It is responsible for $80 \%$ of world trade and is thus vital to the supply chain. Shipping is the most efficient, reliable and effective means of transport, particularly for keeping the supply chain open so that the cargo and goods that the world needs every day can be delivered, which is of special importance during such challenging times as the COVID-19 pandemic.

Global shipping depends on nearly 2 million seafarers worldwide, who make it possible for the world to receive the goods and products needed for everyday life.

The Maritime Labour Convention, 2006, as amended (MLC 2006), of the International Labour Organization (ILO), is the global instrument that sets out seafarers' rights and their working and living conditions on board ship. The MLC 2006, defines a "seafarer" as "any person who is employed or engaged or works in any capacity on board a ship to which this Convention applies". This coverage is broad and includes not only seafarers in the merchant marine but also those working in the cruise industry. The only exceptions are ships engaged exclusively in inland waters, fishing, traditional ships and warships. ${ }^{2}$

The coming together of all maritime stakeholders to collectively address the pandemic and minimize the risks for global trade and human health is an exceptional example of how uniting to face a common enemy-COVID-19- has been and continues to be in the common interest of all countries, governments, relevant international organizations and maritime stakeholders.

There has been extraordinary cooperation among all the relevant United Nations agencies - the International Maritime Organization (IMO), International Labour Organization (ILO), World Health Organization (WHO) and International Civil Aviation Organization (ICAO) - maritime stakeholders and in particular shipping and ports, to collectively address the pandemic and minimize the risk for global trade and on human health.

This article provides an overview of the global response to COVID-19 and its impact on shipping. It points to the importance of a broader appreciation of the role of seafarers as essential frontline workers during this and future pandemics and crises. It examines the action taken by the relevant United Nations agencies, national governments and the maritime industry to address the impact of COVID-19, as well as the challenges to global governance that have arisen as a result of the pandemic.

\footnotetext{
$\overline{{ }^{1} \mathrm{https} / / \mathrm{www} . e c d c . e u r o p a . e u / e n / g e o g r a p h i c a l-d i s t r i b u t i o n-2019-n c o v-c a s e s}$

2 Article II, paragraph 4, of the MLC 2006, provides that the Convention does not apply to warships or naval auxiliaries, ships which navigate exclusively in inland waters or waters within, or closely adjacent to, sheltered waters or areas where port regulations apply, to ships engaged in fishing or in similar pursuits or to ships of traditional build such as dhows and junks.
} 


\section{Critical issues affecting international shipping during the pandemic}

The critical issues that have affected the international shipping sector during the pandemic include border closures to airlines and port closures to cruise ships; quarantine requirements and restrictions on personnel crossing borders in some countries; crew changeover and repatriation for seafarers, including those working on cruise ships and yachts; certification and licensing of seafarers; and resupply, repairs, ship surveys and certification.

\subsection{Crew changeover}

If shipping is to fulfil its vital role in maintaining the operation of the global supply chain, it is essential to ensure that crews can be changed at the required intervals. However, restrictions adopted at the national level, which have in some cases prevented seafarers from disembarking to carry out crew changes, have resulted in seafarers' service on board ship being extended for many months at sea, well beyond the established limits. In many cases, it has not been possible to replace seafarers after long tours of duty or to repatriate them by air to their home countries. Such situations are unsustainable for the safety and well-being of crewmembers and the safe operation of maritime trade.

In accordance with Standard A2.4 of the MLC 2006, seafarers have the right to annual leave of a minimum of 2.5 calendar days per month of employment. The maximum period of service on board ship for seafarers following which they are entitled to repatriation, in accordance with Standard A.2.5, must be less than 12 months.

It should also be noted that, in accordance with the ILO Seafarers' Identity Documents Convention (Revised), 2003, as amended (No. 185) ${ }^{3}$, seafarers are entitled to a unique travel document. Although Convention No. 185 has only been ratified by 35 countries, its predecessor Convention No. $108,{ }^{4}$ which is still in force, has been ratified by 64 countries, making a total of 104 countries committed to accepting seafarers' identity documents ("SIDs"). These two Conventions establish the right for seafarers engaged in international trade to have access to shore facilities and shore leave, which are vital for their general well-being, and therefore in ensuring safer shipping on cleaner oceans. Being able to go ashore after the agreed period of service is essential for seafarers. One of the important objectives of SIDs is to facilitate shore leave. A valid SID, accompanied by a valid passport, entitles the seafarer to transit and transfer to another ship, to transit to join a ship in another country or to be repatriated (see Doumbia-Henry (2003). While public health concerns may well be a reason to deny permission for seafarers to come ashore for shore leave, the refusal to allow seafarers to come ashore for purposes of transit and transfer, as well as for crew replacement, even in the context of the global pandemic, is inhumane and contrary to the letter and spirit of these instruments.

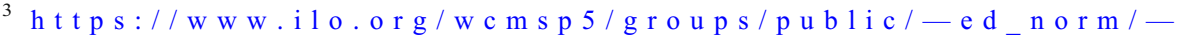
normes/documents/normativeinstrument/wcms 566427.pdf

${ }^{4}$ The Seafarers' Identity Documents Convention, 1958 (No. 108).
} 
Governments need to ensure that effective and safe crew changes can be made so that supply chains remain open. Each month, around 150,000 seafarers need to be changed over and therefore to transit to and from the ships that they operate, in accordance with international maritime regulations for safety, crew health and welfare, and to prevent fatigue (IMO 2020a). By mid-June 2020, some 300,000 seafarers required international flights for crew changeover. In addition, 70,000 seafarers on board cruise ships have been awaiting repatriation. Moreover, crew on commercial fishing vessels, which provide a major source of global nutrition, must also be periodically changed to avoid fatigue (IMO 2020b). As at 10 June 2020, only $30 \%$ of governments worldwide were allowing crew changes to take place. This situation is unsustainable, both for the safety and well-being of seafarers and the safe operation of maritime trade.

\subsection{Abandonment of seafarers}

The abandonment of seafarers is among the concerns that have arisen during the pandemic, for example, in the case of a Spanish flagged ship with 15 seafarers aboard. ${ }^{5}$ Some governments have taken action to repatriate their seafarers, including the Government of India, which repatriated 20,000 seafarers in three phases by the end of May 2020.

The International Transport Workers' Federation (ITF), ${ }^{6}$ which represents seafarers worldwide, has made a call to protect and treat seafarers - frontline workers - with dignity in the same way as other workers on the frontline. It has also raised concerns relating to the impact of the closure of embassies in a number of countries, which has left seafarers with no access to assistance in ports.

\subsection{Cruise ships}

The cruise industry, a critical sector of the transport industry, has also been severely impacted by the pandemic. Unlike other types of merchant shipping, it has had to suspend operations worldwide. In some countries, cruise ships have been banned from entering territorial waters. For example, Canada has banned cruise ships until the autumn of $2020 .^{7}$ Thousands of seafarers have had to stay on board cruise ships, as they have not been allowed to disembark in ports for repatriation to their home countries. Many of these seafarers have not been paid. The seafarers concerned have suffered great anxiety, social isolation and stress, which has had an impact on their mental health, and in some cases has led to suicide. ${ }^{8}$

\subsection{Ports}

Merchant shipping, fishing and the cruise industry all need ports at which to load or unload cargo, fish and passengers, respectively. Since the onset of the pandemic, ports around the world have reported a huge decline in calls by container, passenger and

\footnotetext{
$\overline{{ }^{5} \text { https://www.ilo.org/dyn/normlex/en/f?p=NORMLEXPUB:12100::NO:12100:P12100_ILO_CODE:C108 }}$ :NO

${ }^{6}$ ITF, "Abandoned at sea in the midst of a pandemic", News, 22 April 2020

${ }^{7}$ Transport Canada, "Minister Garneau announces updated measures for cruise ships and passenger vessels in Canadian waters up to October 31, 2020", News Release, 29 May 2020

8 "Crew change", ITF and JNG joint statement, 14 May 2020
} 
cruise ships (Notteboom and Pallis 2020). As at 22 May 2020, there had been a decline of $61-62 \%$ in port capacity utilization around the world, due in particular to the fall in passenger calls (WPSP 2020). However, many ports are now seeing a return to work.

\section{Global governance and the response to the impact of COVID-19 impact on shipping}

The view has recently been expressed that (Blanco and Rosales 2020) "in the wake of the current COVID-19 crisis, governance mechanisms at different scales are demonstrating problems of coordination, uneven capacities and claims of authority. Similarly, the social and economic dimensions of the crisis are affecting countries and communities differently, due to different levels of preparedness of their health, social security systems and infrastructure capacity".

Yet, on the positive side, the response by the entire maritime industry to the pandemic has been exceptional. The industry has come together and developed new protocols to lift barriers to crew changes. ${ }^{9}$ The IMO Secretary-General has endorsed a series of protocols drawn up by a broad cross section of global industry associations representing various sectors of the maritime transport industry. ${ }^{10}$ The protocols contain general measures and procedures designed to ensure that ship crew changes can take place safely during the pandemic. Shipping companies, governments and the relevant national authorities are requested to comply with and adhere to the applicable measures and to do everything possible to allow crew changes to take place. The recommendations made apply to maritime administrations and other relevant national authorities, such as health, customs, immigration, border control, seaport and civil aviation authorities. They address the roles of shipping companies, agents and representatives, including crewing agencies and seafarers, and cover seaports, airports and airlines involved in travel operations for ship crew changes.

\subsection{United Nations (UN) agencies}

One of the most significant areas that deserves to be highlighted in relation to the impact of COVID-19 on the maritime industry is the cooperation, collaboration and solidarity shown by the relevant United Nations agencies.

In response to the pandemic and its implications, the IMO, ILO, WHO and ICAO have joined forces to address the issues falling within their respective mandates to ensure that effective and holistic guidance has been provided to governments and the maritime industry.

\subsection{WHO}

On 24 February 2020, the WHO provided guidance on managing COVID-19 cases on board ships, on the basis of the Handbook for the management of public health events

\footnotetext{
${ }^{9}$ The protocols for crew change and repatriation were drawn up by the ICS, IAPH, BIMCO, IFSMA, INTERTANKO, P\&I Clubs, CLIA, INTERCARGO, InterManager, IPTA, IMCA, INTERFERRY, FONASBA, ITF and WSC. They also take into account input from the International Air Transport Association (IATA).

${ }^{10}$ IMO, Circular Letter No.4204/Add. 14, op. cit.
} 
on board ships (IMO 2020c). The WHO International medical guide for ships (WHO 2007) supports one of the main principles of the MLC 2006, namely, the requirement to ensure that seafarers are provided with health protection and medical care that is as comparable as possible to that generally available to workers ashore, including prompt access to the necessary medicines, medical equipment and facilities for diagnosis and treatment and to medical information and expertise.

\subsection{IMO}

In response to requests from Member States for uniform recommendations on how to address certain issues, by 25 June 2020, the IMO had issued 23 Circular Letters addressing the effects of the pandemic. ${ }^{11}$ These include joint statements with other UN agencies, as well as guidance issued by the shipping industry. It has also ensured the global distribution of all relevant guidance and information and established a Seafarer Crisis Team. On 20 April 2020, the IMO Secretary-General wrote to all Member States of the Organization urging them to recognize seafarers as "key workers", to remove any barriers to their documentation and to lift travel restrictions so that they can return home at the end of their contracts of employment and rejoin their families (IMO 2020d).

In his communications on this subject, the IMO Secretary-General highlighted two important concerns:

1. The crucial importance that the flow of commerce by sea should not be unnecessarily disrupted. At the same time, the safety of life at sea and protection of the marine environment must also remain paramount.

2. The importance of remembering the hundreds of thousands of seafarers on ships who are unwittingly on the front line of the global pandemic. Their professionalism ensures that the goods we all need are delivered safely and with minimal impact on our precious environment. These are people who are usually far from home and family. Their own health and welfare is as important as that of anyone else.

On 8 June, the IMO Secretary-General and the Secretary-General of the United Nations Conference on Trade and Development (UNCTAD) called on governments to facilitate crew changes and ensure crew well-being by facilitating repatriation and the safe return home of seafarers, marine personnel, fishing vessel personnel, offshore energy sector personnel and service provider personnel at ports as "key workers" providing an essential service, regardless of nationality when in their jurisdiction, and to exempt them from travel restrictions. They emphasized that such a designation would ensure that trade in essential goods, including medical supplies and food, is not hampered by the pandemic and associated containment measures (IMO and UNCTAD 2020).

They called for a practical and pragmatic approach to issues of crew changeovers, resupply, repairs, survey and certification and the licensing of seafarers. ${ }^{12}$

\footnotetext{
${ }_{11}^{11}$ See the IMO webpage on the Coronavirus disease (COVID-19) pandemic.

${ }^{12} \mathrm{Ibid}$
} 


\subsection{ILO}

The MLC 2006, as the global instrument setting out seafarers' rights and working and living conditions on board ships, establishes, inter alia, the rights of seafarers to safety and health, a maximum period of service on board, paid sick leave, shore leave, welfare facilities and repatriation. Unfortunately, these rights have not always been guaranteed in practice during the pandemic.

On 7 April, the ILO published an Information Note on maritime labour issues and coronavirus (COVID-19), including a joint statement of the Officers of the Special Tripartite Committee of the MLC 2006, as amended (ILO 2020). The note is intended to provide "guidance on how best to address the complexities of the current crisis in light of the provisions" of the MLC 2006. ${ }^{13}$ The consultations held for this purpose, which are provided for under the MLC 2006, were "seen as a necessary and important approach to ensuring that all countries, irrespective of national circumstances, can engage with the international legal system and that international obligations are respected and implemented, to the extent possible, while efforts continue to be made to improve existing conditions. Governments are thus strongly encouraged to consult national seafarers' and shipowners' organizations in order to address a number of issues in the current context created by the COVID-19 pandemic in light of the MLC 2006."14

The Information Note explains that, for States parties to the MLC 2006, under the terms of the Convention non-compliance with the MLC 2006, is only possible in circumstances of force majeure, which is "the occurrence of an irresistible force or of an unforeseen event, beyond the control of the State, making it materially impossible in the circumstances to perform the obligation". ${ }^{15}$ In the context of the pandemic, it notes that "the current circumstances might render compliance with some of the obligations set out in the MLC 2006, materially impossible" and that "these circumstances could constitute cases of force majeure" (see also, United Nations (2001). However, these circumstances "do not annul or terminate the obligation", but "provide a justification or excuse for non-performance while the circumstance in question subsists". In such a case, compliance must resume as "soon as the factors causing and justifying the nonperformance are no longer present". 16

The parties involved should therefore make every attempt to comply with their obligations under the MLC 2006, and non-compliance can only be excused when compliance is materially and objectively impossible by reason of the occurrence of an irresistible event. $^{17}$

\subsection{ICAO}

On 26 May 2020, three international organizations, IMO, ILO and ICAO, published common guidance relating to COVID-19 which takes into account the WHO Medical

\footnotetext{
13 Ibid

14 Ibid, para. 4.

${ }^{15}$ Ibid, para 5, where reference is made in footnote 6 to the United Nations, Yearbook of the International Law Commission, 2001, Vol. II, Part Two, Article 23, p. 27

${ }^{16} \mathrm{Ibid}$, para 5, where reference is made in footnote 7 to the United Nations, Yearbook of the International Law Commission, 2001, op. cit.

${ }^{17}$ Ibid., p. 5
} 
Guide for Ships. The guidance calls for the facilitation of crew changes in ports and through airports in the context of the pandemic (IMO 2020e). By mid-June, an estimated 150,000 seafarers were still awaiting international flights for crew changes. This is considered to be one of the greatest challenges faced by the shipping industry, as COVID-19 border closure restrictions mean that large numbers of seafarers have had to extend their service on board ship after many months at sea. The joint statement by the three organizations is an excellent example of cooperation at the global level between United Nations agencies.

\section{Response by governments and the industry}

\subsection{Governments}

At their summit on 26 March 2020, addressing disruptions in international trade in the context of the pandemic, the G20 leaders reaffirmed that:

Consistent with the needs of our citizens, we will work to ensure the flow of vital medical supplies, critical agricultural products, and other goods and services across borders, and work to resolve disruptions to the global supply chains, to support the health and well-being of all people.

We commit to continue working together to facilitate international trade and coordinate responses in ways that avoid unnecessary interference with international traffic and trade. Emergency measures aimed at protecting health will be targeted, proportionate, transparent, and temporary. We task our Trade Ministers to assess the impact of the pandemic on trade.

We reiterate our goal to realize a free, fair, non-discriminatory, transparent, predictable and stable trade and investment environment, and to keep our markets open. ${ }^{18}$

Following this powerful message from the G20 leaders, action has been taken by over 50 countries, including Singapore and the UK, ${ }^{19}$ to enable seafarers to disembark for medical care and for transfer and transit to their home countries. For example, the Government of Singapore has officially recognized the important role of maritime personnel and has explored initiatives to improve support for seafarers. The nationwide ban on entry or transit through Singapore has been reviewed, and crew changes are now allowed under special circumstances (Hand 2020). It is hoped that many other governments will follow suit.

\subsection{The maritime industry}

The response to COVID-19 by the stakeholders in the maritime industry deserves praise and reflects their shared interest in working together with the relevant United Nations agencies to provide comprehensive and coherent guidance to member States,

\footnotetext{
${ }^{18}$ G20 Leaders' Statement, "Statement on COVID-19”, Extraordinary Leaders' Summit, 26 March 2020.

${ }^{19}$ Nautilus International, "Covid-19: UK government designates seafarers as key workers", News, 20 March 2020
} 
shipowners' and seafarers' organizations and other non-governmental organizations, to limit the impact of the pandemic on the industry and particularly on seafarers.

The stakeholders in the maritime industry, including the International Chamber of Shipping (ICS) and the ITF, have provided common guidance for shipowners and seafarers. ${ }^{20}$ They prepared a preliminary list of recommendations for governments and relevant national authorities on the facilitation of maritime trade during the COVID-19 pandemic with a view to keeping key supply chains open and maritime trade, transport and services moving. ${ }^{21}$ The ICS has also prepared a series of guidance documents that have been published by the IMO, including guidance for ship operators for the protection of the health of seafarers. ${ }^{22}$

The stakeholders in the maritime industry have called on governments to ensure that, when implementing measures to protect public health and address COVID-19, they do not introduce obstacles to ship and port operations, including the movement of seafarers and marine personnel, as defined by IMO instruments and the MLC 2006. In relation to crew changes, shipowners' and seafarers' organizations have jointly urged governments to facilitate crew changeover and the repatriation of seafarers (IMO 2020f). In this respect, a number of measures have been identified as being necessary, including access to berths in ports; facilitating crew changes in ports; facilitating port and related operations; and health protection measures in ports. ${ }^{23}$

Most of the 22 Circular Letters issued by the IMO were prepared by the maritime stakeholders. ${ }^{24}$ The IMO, ILO, ICAO and WHO, working with the maritime stakeholders, including governments, have also provided guidance for member States, the shipping, fishing, ports and aviation industries, covering a range of issues that need to be taken into account.

The human element has featured prominently in the guidance provided, considering that seafarers are the ones who make shipping possible and enable the goods that are needed to be supplied to all countries around the world, including land-locked countries, for which goods arrive in the ports of third countries and are then transported by land.

During the pandemic, it is crucial for all personnel involved to be protected from infection, including those on board ships and shore personnel who may need to board ships temporarily or interact with seafarers. The objective is to ensure the necessary openness to the requirements of each of the parties for the management of the risks involved, which necessitates a pragmatic resolution of differences regarding requirements and expectations.

In a Circular Letter of 27 March 2020, the IMO Secretary-General reiterated earlier calls and emphasized the crucial importance of ensuring that the flow of commerce by sea is not unnecessarily disrupted. He recalled that seafarers are on the front line during the global pandemic and that a practical and pragmatic approach is required in such

\footnotetext{
${ }^{20}$ See the ICS coronavirus website.

${ }^{21}$ IMO, Circular Letter No. 4204/Add. 6, 27 March 2020

${ }^{22}$ IMO, Circular Letter No. 4204/Add. 4/Rev. 1, 28 May 2020

23 Ibid

${ }^{24}$ The COVID-19 related guidelines for ensuring a safe shipboard interface between ship and shore based personnel were proposed by a broad cross section of global industry associations in consultative status with IMO: ICS, IAPH, BIMCO, IACS, IFSMA, IMPA, INTERTANKO, P\&I Clubs, CLIA, INTERCARGO, InterManager, IPTA, FONASBA, and WSC; with input from the International Maritime Employers' Council (IMEC) and the International Support Vessel Owners Association (ISOA).
} 
unusual times to such issues as crew changeovers, resupply, repairs, survey and certification, and the licensing of seafarers. ${ }^{25}$

The WHO has provided guidance on the safe and effective use of personal protective equipment (PPE) in support of decisions to require the use of PPE to minimize the risk of infection for seafarers, marine personnel, fishing vessel personnel, passengers and others on board ships. The guidance also applies to shore personnel who board ships, such as pilots, port workers, port State control officers and ships' agents (IMO 2020g).

In consultation with the IMO and the ILO, port State control (PSC) regimes have agreed to help resolve the urgent issue of crew changes and the repatriation of seafarers and to address the issues surrounding surveys and certificate renewals during the pandemic (IMO 2020h). While port State control regimes generally consider that crew changes and repatriation are not directly under their remit, they have agreed that they can play an important role through their inspections on board ships in monitoring and enforcing compliance with international regulations. For example, port State control regimes may examine safety issues resulting from crew fatigue, especially in cases where the extension of seafarers' contracts is in violation of the maximum periods set out in the MLC 2006. Port State control regimes also consider that they are in a position to provide valuable information on specific situations.

Taking into account differences in national requirements, a straightforward system is proposed for the evaluation of risks and the communication of the control measures to be put in place, by mutual agreement, to reduce the risk of infection. Simple steps and precautions are recommended if presence on board a ship is unavoidable, including minimizing the number of persons boarding the ship; using outer walkways rather than access through the crew accommodation; frequent handwashing; and the maintenance of social distancing. The dissemination by the IMO of the Singapore Crew Change Guidebook has also been welcomed (IMO 2020i).

\section{Conclusion}

For the foreseeable future, COVID-19 will continue to have a huge impact on the shipping industry, including the cruise ship sector, and therefore also on world trade and travel. Its impact on seafarers worldwide, whether in the maritime or port sectors, has been devastating. Government responses, based on their concerns for the health of citizens, have shown the limits of cooperation. At the beginning of the pandemic, many countries closed their maritime space to shipping, resulting in health and safety concerns for seafarers. And yet, seafarers are unsung heroes of the pandemic. The lessons learnt include the need to give greater recognition to seafarers, who tend to be out of sight and out of mind, except for their families, but on whom we rely for the goods that are needed everyday and who make global trade possible.

The action that is taken must ensure that there is a more robust maritime sector for the future. It is clear that there will now be an increased need to move forward with greater integration of the global supply chain, digitalization, standardization, the development of single windows to simplify the submission of the information required

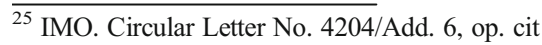


by the authorities for cargo formalities and to facilitate and reduce the administrative burden for ship data providers.

As the pandemic has affected every country throughout the world, the development of a common approach to addressing the challenges of keeping citizens safe and economies alive will offer lessons which, if learnt, will certainly ensure a better future for humanity as a whole.

\section{Annex 1}

\section{IMO Circular Letters relating to COVID-19}

Since the COVID-19 outbreak, the IMO Secretary-General has issued 22 Circular Letters providing guidance to the maritime industry and advice for IMO Member States, seafarers and shipping:

1. Circular Letter No.4204/Add.22 (11 June 2020) - Coronavirus (COVID-19) Singapore Crew Change Guidebook

2. Circular Letter No.4204/Add.21 (8 June 2020) - Joint statement IMOUNCTAD - Call for collaborative action in support of keeping ships moving, ports open and cross-border trade flowing during the COVID-19 pandemic

3. Circular Letter No.4204/Add.20 (5 June 2020) - Coronavirus (COVID-19) Accelerating digitalization of maritime trade and logistics - A call to action

4. Circular Letter No.4204/Add.19 (2 June 2020) - Coronavirus (COVID-19) Guidance for flag States regarding surveys and renewals of certificates during the COVID-19 pandemic

5. Circular Letter No.4204/Add.18 (26 May 2020) - Joint Statement IMO-ICAOILO on designation of seafarers, marine personnel, fishing vessel personnel, offshore energy sector personnel, aviation personnel, air cargo supply chain personnel and service provider personnel at airports and ports as key workers, and on facilitation of crew changes in ports and airports in the context of the COVID-19 pandemic

6. Circular Letter No.4204/Add.17 (21 May 2020) - Coronavirus (COVID 19) Preparing for post COVID-19 operations: considerations and practicalities for port community systems, single window and other electronic exchange platforms

7. Circular Letter No.4204/Add.16 (6 May 2020) - Coronavirus (COVID 19) COVID-19 related guidelines for ensuring a safe shipboard interface between ship and shore-based personnel

8. Circular Letter No.4204/Add.15 (6 May 2020) - Coronavirus (COVID 19) Personal protective equipment

9. Circular Letter No.4204/Add.14 (5 May 2020) - Coronavirus (COVID-19) Recommended framework of protocols for ensuring safe ship crew changes and travel during the coronavirus (COVID-19) pandemic

10. Circular Letter No.4204/Add.13 (5 May 2020) - Coronavirus (COVID-19) Recommendations for Governments and relevant national authorities on 
facilitating the movement of offshore energy sector personnel during the COVID-19 pandemic

11. Circular Letter No.4204/Add.12 (27 April 2020) - Coronavirus (COVID 19) Declaration by Port Authorities Roundtable (PAR) members in view of the global COVID-19 situation

12. Circular Letter No.4204/Add.11 (24 April 2020) - Coronavirus (COVID 19) EC Guidelines on protection of health, repatriation and travel arrangements for seafarers, passengers and other persons on board ships

13. Circular Letter No.4204/Add.10 (22 April 2020) - Joint Statement IMOWHO-ILO on medical certificates of seafarers, ship sanitation certificates and medical care of seafarers in the context of the COVID-19 pandemic

14. Circular Letter No.4204/Add.9 (16 April 2020) - Joint Statement IMO-WCO on the integrity of the global supply chain during the COVID-19 pandemic

15. Circular Letter No.4204/Add.8 (14 April 2020) - Coronavirus (COVID-19) - Video meeting with port State control (PSC) regimes (includes joint statement and statements and/or relevant temporary guidance issued by the United States, the Acuerdo de Viña del Mar and the Caribbean, Indian Ocean, Mediterranean, Paris and Tokyo MOUs

16. Circular Letter No.4204/Add.7 (3 April 2020) - Coronavirus (COVID-19) - Guidance concerning unforeseen delays in the delivery of ships

17. Circular Letter No.4204/Add.6 (27 March 2020) Coronavirus (COVID-19) - Preliminary list of recommendations for Governments and relevant national authorities on the facilitation of maritime trade during the COVID-19 pandemic

18. Circular Letter No.4204/Add.5/Rev.1 (2 April 2020) Coronavirus (COVID-19) - Guidance relating to the certification of seafarers and fishing vessel personnel

19. Circular Letter No. 4202/Add.4/Rev.1 (5 March 2020) contains ICS Coronavirus (COVID-19) Guidance for ship operators for the protection of the health of seafarers

20. Circular Letter No.4204/Add.3 (2 March 2020) - Operational considerations for managing COVID-19 cases/outbreak on board ships

21. Circular Letter No.4204/Add.2 (21 February 2020) contains the Joint Statement IMO-WHO on the Response to the COVID-19 Outbreak and encourages Member States and international organizations to disseminate it as widely as possible. Available in the six official languages of the United Nations system.

22. Circular Letter No.4204/Add.1 (19 February 2020) provides advice on Implementation and enforcement of relevant IMO instruments

23. Circular Letter No.4204 (31 January 2020) providing information and guidance, based on recommendations developed by the World Health Organization (WHO), on the precautions to be taken to minimize risks to seafarers, passengers and others on board ships from the coronavirus. 


\section{Annex 2}

Advice and information for seafarers and shipping from the ILO and other organizations is also available through the following links

- $\quad$ BIMCO - https://www.bimco.org/covid19

- BIMCO - crew challenges - https://www.bimco.org/ships-ports-and-voyageplanning/crew-support/health-and-medical-support/novel-coronavirus $\% 2 \mathrm{D} \% 2 \mathrm{D}$ crew-challenges

- Chemical Distribution Institute (CDI), Oil Companies International Marine Forum (OCIMF), INTERTANKO - Temporary Covid-19 Precautions During an Inspection (PDF)

- Chemical Distribution Institute (CDI), Oil Companies International Marine Forum (OCIMF), INTERTANKO - Temporary Guidelines for Conducting a Vessel Inspection During Covid-19 (PDF)

- EMSA - http://emsa.europa.eu/news-a-press-centre/covid19.html

- European Commission - Guidelines on protection of health, repatriation and travel arrangements for seafarers, passengers and other persons on board

https://ec.europa.eu/transport/modes/maritime/news/2020-04-08-coronaviruscruise-ships_en

- European Commission - Guidelines on protection of health, repatriation and travel arrangements for seafarers, passengers and other persons on board ships (PDF download)

- European Commission - Guidelines concerning the exercise of the free movement of workers during COVID-19 outbreak (PDF download)

- Helse Bergen Haukeland University Hospital COVID-19 assessment tool - www. covid19atsea.no

- IACS - http://www.iacs.org.uk/covid-19/

- International Chamber of Shipping (ICS) - Coronavirus (COVID-19) Guidance for Ship Operators for the Protection of the Health of Seafarers

- International Labour Organization (ILO) - COVID-19 and maritime shipping \& fishing - https://www.ilo.org/sector/Resources/publications/WCMS_742026 /lang\%2D\%2Den/index.htm

- International Labour Organization (ILO) Information note on maritime labour issues and coronavirus (COVID-19) (PDF)

- International Maritime Health Association (IMHA) - advice for shipping companies on the new type of coronavirus (2019-nCoV)

- INTERTANKO - Covid-19 Tanker Recovery Management Plan (Download PDF)

- INTERTANKO - INTERTANKO Crew Change Management Plan (Download PDF)

- INTERTANKO - Outbreak Management Plan: Covid-19 (Download PDF)

- ISWAN - VIDEO "Managing Your Mental Health During the Covid 19 Pandemic - A guide for seafarers" on YouTube. Mental health tools are also available to download free of charge from the ISWAN website at https://www.seafarerswelfare. org/seafarer-health-information-programme/good-mental-health

- International Transport Forum at the OECD - Transport and COVID-19: Responses and resources - https://www.itf-oecd.org/covid-19 
- International Transport Workers Federation (ITF) - COVID-19 update for transport workers: https://www.itfglobal.org/en/focus/covid-19

- International Transport Workers Federation (ITF) - COVID-19 country information for seafarers: https://www.itfseafarers.org/en/embed/covid-19-country-informationseafarers

- USCG - https://www.uscg.mil/coronavirus/

- S5 - port restrictions map - http://tiny.cc/zz07lz

- Singapore - https://www.mpa.gov.sg/web/portal/home/maritime-singapore/whatmaritime-singapore-offers/covid-19_for_maritime_community

- Safety4Sea - https://safety4sea.com/cm-how-coronavirus-affects-shippingeverything-you-need-to-know/

- Steamship Mutual et al - VIDEO - Coronavirus - Stay Safe on Board - https://www. steamshipmutual.com/loss-prevention/stay_safe_on_board_0420.htm

- UNCTAD - Port Responsiveness in the fight against COVID-19 - Technical note - https://tt.unctad.org/ports-covid-19/

- UN World Food Programme - World travel restrictions - http://unwfp.maps.arcgis. com/apps/opsdashboard/index.html\#/db5b5df309ac4f10bfd36145a6f8880e

- WaterFront - COVID-19 overview crew change impact - https://www.waterfront$\mathrm{ms} . \mathrm{com} / \mathrm{crew}$-change-impact/2/

- Wilhelmsen COVID-19 Global Port Restrictions Map - https://www.wilhelmsen. com/ships-agency/campaigns/coronavirus/coronavirus-map/

- World Ports COVID-19 Information Portal - https://sustainableworldports. org/world-ports-covid19-information-portal/

\section{References}

Blanco ML, Rosales A (2020) "Global governance and COVID-19: The implications of fragmentation and inequality", E-International Relations, 6 May 2020

Doumbia-Henry C (2003) Current maritime labour law issues: An internationally uniform identity document for seafarers. WMU J Marit Aff 2(2):129-148

Hand M (2020) "Singapore to allow crew changes where seafarer contracts have expired". Seatrade Maritime News, 25

ILO (2020) "Information note on maritime labour issues and coronavirus (COVID-19), including a joint statement of the Officers of the Special Tripartite Committee of the Maritime Labour Convention, 2006, as amended", 7

IMO (2020a) Circular Letter No. 4204/Add. 14, "Coronavirus (COVID-19) -Recommended framework of protocols for ensuring safe ship crew changes and travel during the coronavirus (COVID-19) pandemic", 5 May 2020a.

IMO (2020b) Circular Letter No. 4204/Add. 14, "Coronavirus (COVID-19) - Recommended framework of protocols for ensuring safe ship crew changes and travel during the coronavirus (COVID-19) pandemic", 5 May

IMO (2020c) Circular Letter No. 4204/Add. 3, "Operational considerations for managing COVID-19 cases/ outbreak on board ships", 2 March 2020c

IMO (2020d) "Personal message from IMO Secretary-General Kitack Lim to seafarers", 20 April 2020

IMO, Circular Letter No.4204/Add. 18, "Joint Statement IMO-ICAO-ILO on designation of seafarers, marine personnel, fishing vessel personnel, offshore energy sector personnel, aviation personnel, air cargo supply chain personnel and service provider personnel at airports and ports as key workers, and on facilitation of crew changes in ports and airports in the context of the COVID-19 pandemic", 26 May 2020e.

IMO, Circular Letter No.4204/Add.14, Recommended framework of protocols for ensuring safe ship crew changes and travel during the coronavirus (COVID-19) pandemic, 5 May $2020 \mathrm{f}$ 
IMO Circular Letter No.4204/Add.15, "Personal protective equipment", 6 May 2020g

IMO, Circular Letter No. 4204/Add. 19, "Guidance for flag States regarding surveys and renewals of certificates during the COVID-19 pandemic", 2 June $2020 \mathrm{~h}$

IMO, Circular Letter No. 4204/Add. 22, "Singapore Crew Change Guidebook", 25 June 2020i.

IMO and UNCTAD (2020) "Joint statement in support of keeping ships moving, ports open and cross-border trade flowing during the COVID-19 pandemic", 8

MLC (2006). https://www.ilo.org/global/standards/maritime-labour-convention/lang-en/index.htm

Notteboom T, Pallis T (2020) "IAPH-WPSP Port Economic Impact Barometer"

United Nations (2001) "Responsibility of States for Internationally Wrongful Acts", 2001, International Law Commission

WHO (2007) International medical guide for ships, 3rd edn, Geneva

WPSP (2020) "Global Survey on impact of COVID19 on ports: Regional differences becoming more pronounced", 22 May 2020

Publisher's note Springer Nature remains neutral with regard to jurisdictional claims in published maps and institutional affiliations. 